\title{
Validation of the CFD model for prediction of flow behaviour in fluidized bed reactors
}

\author{
R. K. Thapa \& B. M. Halvorsen \\ Department of Process, Energy and Environmental Technology, \\ Telemark University College, Norway
}

\begin{abstract}
The aim of this study is to develop a robust CFD model for predicting fluid dynamics in a gasification reactor. Experimental tests are performed. A cylindrical bed with pressure sensors is used in the experimental study. A series of simulations are performed using the commercial CFD tool ANSYS Fluent 12.1. A multi-fluid Eulerian model incorporating the kinetic theory of granular flow is applied in the simulations. Fluidized bed reactors in biomass gasification processes use steam as a fluidizing gas. High temperature makes it difficult to study the flow behaviour under the operating conditions. A cold flow model is constructed to study the fluid dynamics. Air at ambient conditions is used as the fluidizing gas for the cold model. The density and viscosity variation between air at ambient temperature and steam at high temperature results in different flow behaviour. The CFD model is developed to also be able to predict the flow behaviour of steam fluidized beds. Computational minimum fluidization velocity, bed expansion ratio pressure drop and pressure standard deviation agree well with experimental measurements. A computational model has been developed and validated against experimental data. The validated CFD-model can be useful in the study of flow behaviour of high temperature steam fluidized gasification reactors.
\end{abstract}

Keywords: fluidized bed, CFD, multi-fluid Eulerian model.

\section{Introduction}

Gas-solid fluidized bed reactors are widely used in biomass gasification technology. The fluidizing gas in the reactors is steam at high temperature. Study of the flow behaviour inside the hot bed is difficult. Most of the design and 
optimization of the reactors are still based on the empirical methods. Alternatively, down-scaled pilot plants and cold flow models are constructed. In the cold flow model, air at ambient conditions is used as the fluidizing gas. Air at ambient condition and high temperature steam has different density and viscosity. The density and viscosity effect in the flow behaviour and fluidization properties. The computational fluid dynamics (CFD) offers an approach to the prediction of the flow behaviour. A validated model can be applied in the simulation of flow behaviour in a hot steam fluidized reactor. This can reduce the task of constructing pilot-scale and cold flow models.

Eulerian multi-fluid model is becoming more and more accepted in gas-solid fluidized bed simulations [1]. The model incorporating kinetic theory of granular flow considers both gas and solid as interpenetrating fluids. The objective is to establish a comparatively validated model. This requires agreement between the experimental and simulated results on parameters such as pressure drop, pressure standard deviation, bed expansion, minimum fluidization velocity and bubble behaviour.

A number of works on validation of the model have been published [2-6]. A reasonably good agreement between experimental and computational results is reported. The governing equations are mass and momentum balance. However, different drag models and constitutive equations have been used in the models.

A set of the constitutive equation with drag model has been finalized by Jayarathna, S.A. [7]. This option is applied in this work. The computational analysis of minimum fluidization velocity and bubble behaviour using pressure standard deviation and fluctuation of solid volume fraction has been introduced.

\section{Experimental set up}

Experiments are performed in a Plexiglas cylinder with $1.4 \mathrm{~m}$ height and 0.084 $\mathrm{m}$ diameter. The pressure sensors are located along the height of the cylinder and connected to the lab-view program for data storage as shown in Figure 1.

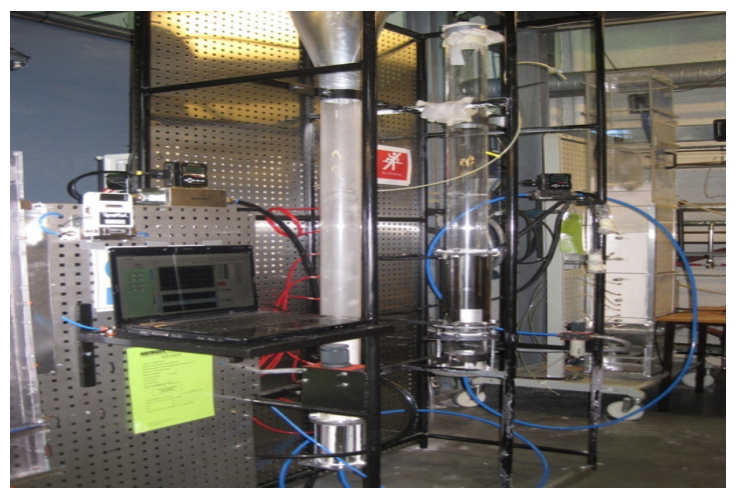

Figure 1: Experimental set-up: fluidized bed with pressure reduction valve, digital flow controller, pressure sensors. 
The air flowing through a uniform air distributer is controlled by the lab-view program in order to maintain a steady flow of gas. The air flow rate is controlled by air flow meter and the data are saved in the lab-view program.

The particles in biomass gasification reactors are quartz sand of mean particle size $500 \mu \mathrm{m}$ and density $2500 \mathrm{~kg} / \mathrm{m}^{3}$. Similar particles are selected in the experimental work.

The physical properties of gas and particles used in the experiments are presented in Table 1. A series of experiments are performed for a wide range of superficial air velocity.

Table 1: $\quad$ Gas and solid properties.

\begin{tabular}{|c|c|c|}
\hline Parameters & Value & Remarks \\
\hline Particle density $\left[\mathrm{kg} / \mathrm{m}^{3}\right]$ & 2500 & Glass \\
\hline Gas density $\left[\mathrm{kg} / \mathrm{m}^{3}\right]$ & 1.225 & Air \\
\hline Gas viscosity & $1.78 \times 10^{-5}$ & Air \\
\hline Particle diameter $[\mu \mathrm{m}]$ & 500 & Mean \\
\hline Initial bed height $[\mathrm{m}]$ & 0.32 & \\
\hline
\end{tabular}

The pressure sensors are located at $0.03,0.13,0.23,0.33 \mathrm{~m}$ above the air distributor as shown in Figure 2.

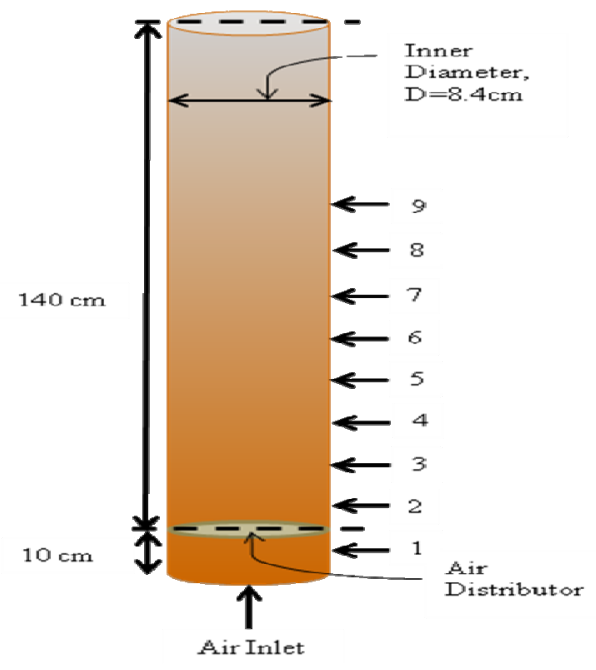

Figure 2: Sketch of $0.084 \mathrm{~m}$ bed with pressure sensors.

\section{Computational model}

A multi-fluid Eulerian model incorporating kinetic theory of solid particles is applied to simulate the transient behavior of the bed. The governing equations 
are the conservation of mass and momentum. The kinetic theory of granular flow considers the conservation of solid fluctuation energy [8]. Simulations are performed with air as fluidizing gas. The particles and properties are consistent to those used in the experiments. The simulation parameters used for the model are presented in Table 2 .

Table 2: $\quad$ Simulation parameters.

\begin{tabular}{|c|c|c|}
\hline Parameters & Value & Remarks \\
\hline Particle density $\left[\mathrm{kg} / \mathrm{m}^{3}\right]$ & 2500 & Glass \\
\hline Gas density $\left[\mathrm{kg} / \mathrm{m}^{3}\right]$ & 1.225 & Air \\
\hline Gas viscosity $[$ Ps.s] & $1.78 \times 10^{-5}$ & Air \\
\hline Particle diameter $[\mu \mathrm{m}]$ & 500 & Mean \\
\hline Restitution coefficient & 0.9 & \\
\hline Initial solid packing & 0.6 & \\
\hline Maximum solid volume fraction $[-]$ & 0.63 & \\
\hline Bed diameter $[\mathrm{m}]$ & 0.084 & \\
\hline Static bed height $[\mathrm{m}]$ & 0.32 & \\
\hline Time step & $1 \times 10^{-3}$ & \\
\hline Number of iterations per time step & 40 & \\
\hline
\end{tabular}

The combination of the models used in the work is summarized in Table 3. The combination of model is validated against the experimental data for different flow conditions [7].

Table 3: $\quad$ Models used in the simulation.

\begin{tabular}{|c|c|}
\hline Drag model & Symlal O'Brien \\
\hline Grannular Bulk Viscosity & Symlal O'Brien \\
\hline Frictional Viscosity & Constant \\
\hline Frictional Pressure & Based-ktgf \\
\hline Solid Pressure & Ma-ahamadi \\
\hline RadialDistribution Function & Ma-ahmadi \\
\hline
\end{tabular}

\section{Results and discussion}

Minimum fluidization velocity is regarded as the most important parameter in the design of fluidized bed reactors [9]. Minimum fluidization velocity $\left(\mathrm{u}_{\mathrm{mf}}\right)$ is experimentally determined plotting average pressure drop across the bed height as a function of superficial air velocity as shown in Figure 3. Experimental measurement of minimum fluidization velocity for the glass particles is about $0.24 \mathrm{~m} / \mathrm{s}$. The pressure drop is $129 \mathrm{mbar}$ and the bed expansion ratio is 1.03 . The pressure drop is proportional to the gas velocity below minimum fluidization condition. 


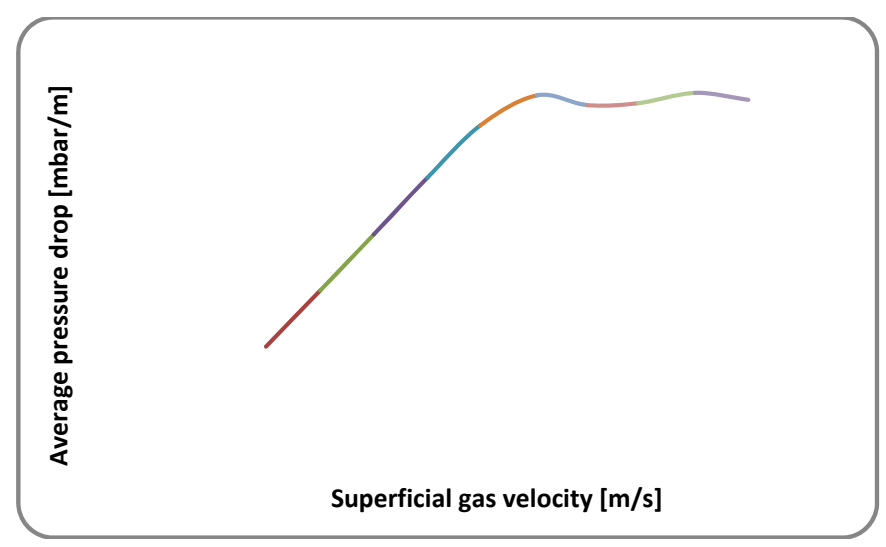

Figure 3: Experimental average pressure drop as a function of superficial gas velocity.

Fig. 4 compares the experimental and computational pressure standard deviation at different level of the bed height. After fluidization conditions, the pressure fluctuation across the bed increases significantly. Pressure standard deviation can be used to determine the minimum fluidization velocity from experimental and computational results. Before fluidization the pressure standard deviation is about zero. It increases with the particle movement in the bed. The experimental and simulated minimum fluidization velocities are about 0.24 and $0.26 \mathrm{~m} / \mathrm{s}$ respectively. The experimental $u_{m f}$ is similar to that in Figure 3 . The deviation between experimental and computational $u_{m f}$ is $8 \%$. The increase in pressure standard deviation with increasing superficial air velocity indicates increasing bubble frequency. The Figure indicates a good agreement of experimental and simulated results concerning the minimum fluidization velocity.

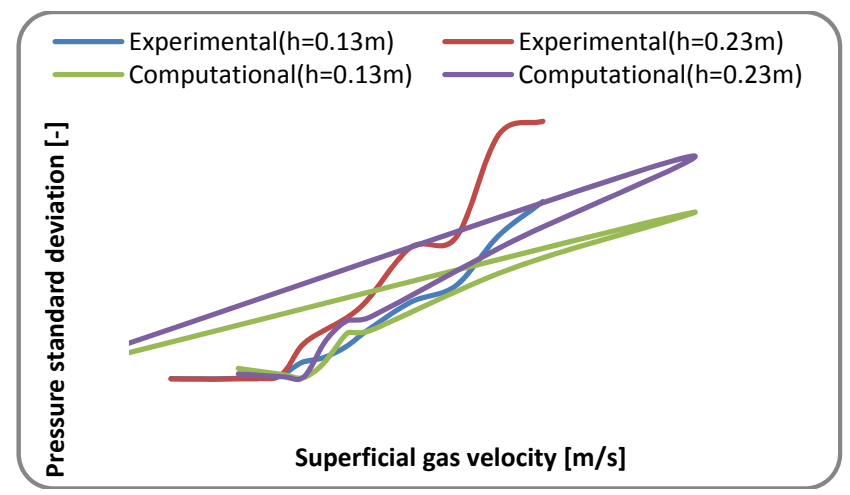

Figure 4: Comparison of experimental and computational pressure standard deviation as a function of superficial air velocity. Bed height $=$ $0.13 \mathrm{~m}$. 
The contour of solid volume fraction at the height of $0.13 \mathrm{~m}$ is presented in Figure 5. The contours are at different superficial air velocity and at $8 \mathrm{~s}$ of real time simulation. Bubbles start to appear at the superficial air velocity $0.28 \mathrm{~m} / \mathrm{s}$. The predicted minimum bubbling velocity is slightly higher than minimum fluidization velocity. The particles used in the study are characterized as Geldart B particles. For Geldart B particles, the minimum fluidization and minimum bubbling velocities are almost the same [9]. Bubble frequency is increased with increasing air velocity. Small bubbles are formed at the bottom of the bed and the size is increased as they rise along the bed height.
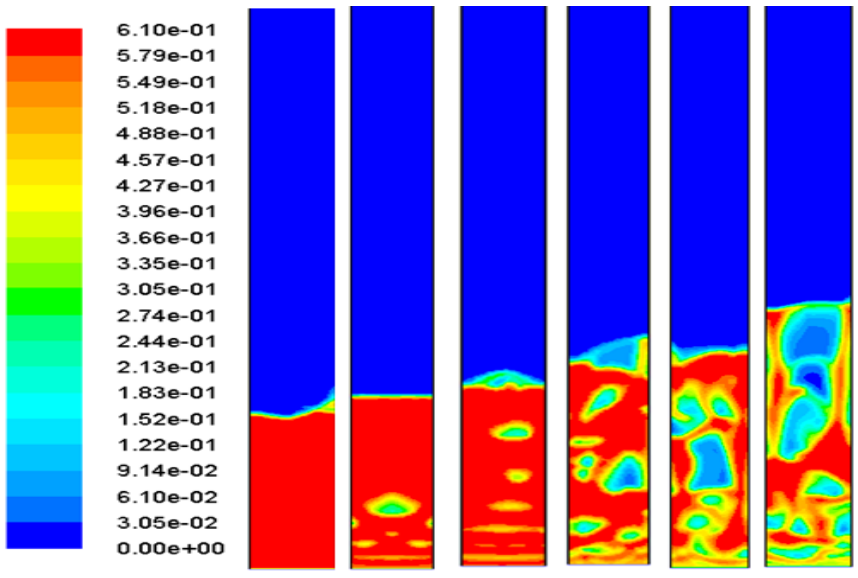

$0.26 \mathrm{~m} / \mathrm{s}$

$0.28 \mathrm{~m} / \mathrm{s} \quad 0.30 \mathrm{~m} / \mathrm{s}$

$0.45 \mathrm{~m} / \mathrm{s} \quad 0.60 \mathrm{~m} / \mathrm{s}$

$0.75 \mathrm{~m} / \mathrm{s}$

Figure 5: Contours of solid volume fraction at different superficial air velocities.

The minimum bubbling velocities are also studied from the plot of time average solid volume fraction from simulation data at the bed height $0.13 \mathrm{~m}$ and $0.23 \mathrm{~m}$. Figure 6 shows the solid volume fraction variation against time at the bed height of $0.23 \mathrm{~m} / \mathrm{s}$.

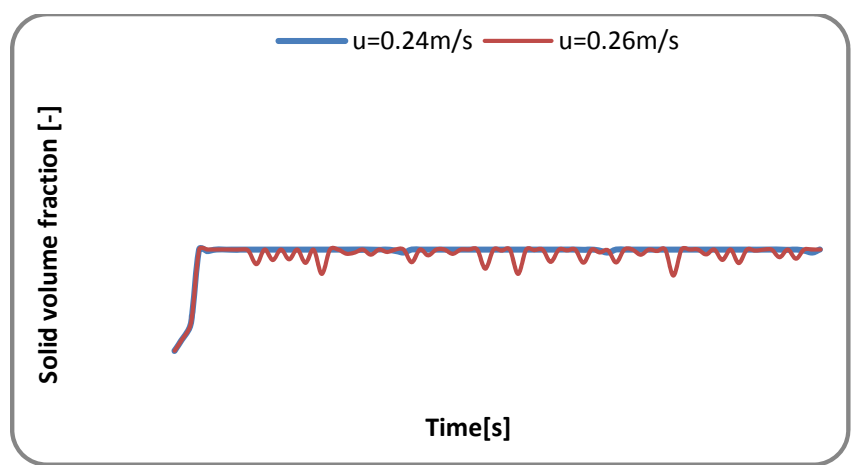

Figure 6: Solid volume fraction fluctuation at lower air velocities. 
At the air velocity of $0.24 \mathrm{~m} / \mathrm{s}$, the solid volume fraction is almost constant as shown in Figure 6. Slight fluctuation of the solid volume fraction starts at the air velocity of $0.26 \mathrm{~m} / \mathrm{s}$ indicating the inception of fluidization.

The solid volume fraction at the superficial air velocity $0.28 \mathrm{~m} / \mathrm{s}$ shows significant fluctuation indicating bubble formation. The bubble frequency is increased at the air velocity $0.30 \mathrm{~m} / \mathrm{s}$.

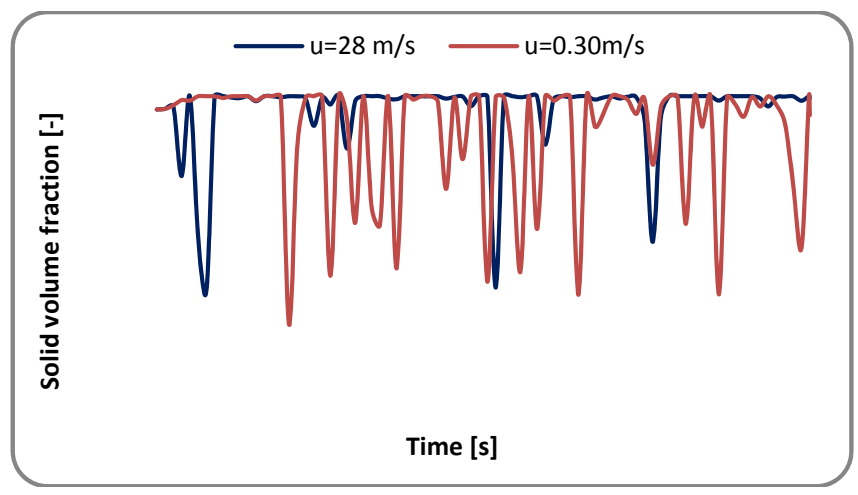

Figure 7: Solid volume fraction as a function at the higher air velocities.

In Fig. 8 computational and experimental pressure drops are compared at the bed height of $0.13 \mathrm{~m}$. The pressure drop show good agreement at the gas velocity above the minimum fluidization. The deviation between the computational and experimental results is $7 \%$ at minimum fluidization. Above the minimum fluidization condition, the deviations are less than 7\%. However, below minimum fluidization the deviation is significant. Eulerian multiphase model considers both the solid and gas as fluids. The model considers the bed fluidizing even at the gas velocity lower than minimum fluidization.

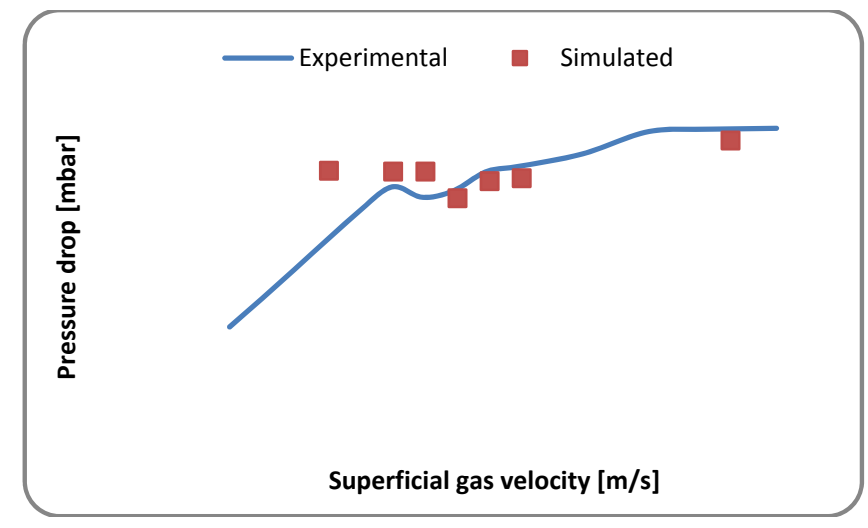

Figure 8: Comparison of experimental and computational pressure drop as a function of air velocity. 
Figure 9 shows a comparison of bed expansion in experiment and simulations. In both cases the bed expansion ratio is increased consistently with superficial air velocity. Simulated bed expansion is slightly lower than experimental. The average deviation of bed expansion between computational and experimental results is about 5\%. At the higher air velocities, the experimental bed expansion is an average expansion. The bed height in the experiments is fluctuating and not constant at higher air velocities.

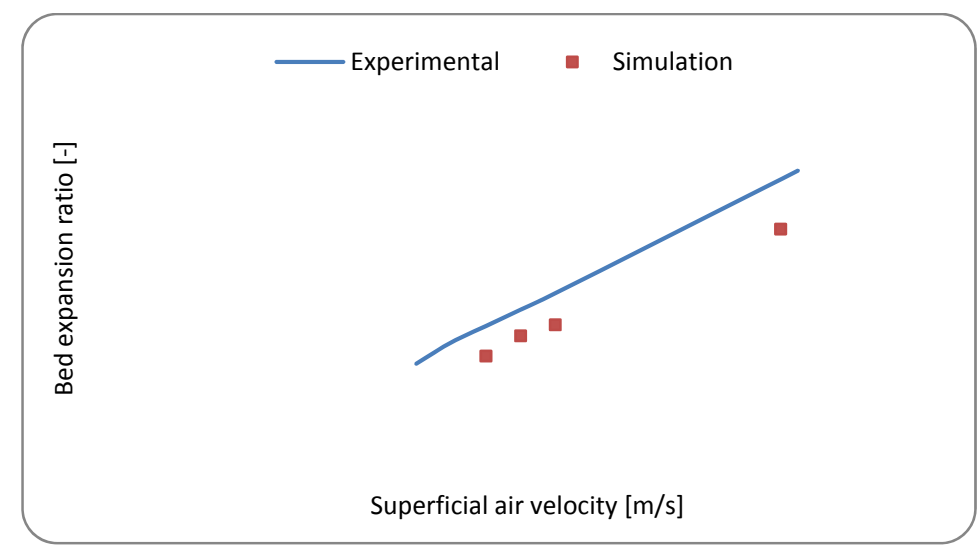

Figure 9: Experimental and simulated bed expansion as a function of superficial air velocity.

\section{Conclusions}

A multifluid Eulerian model incorporating the kinetic theory of granular flow is applied for computational prediction of gas-solid flow behaviour. The results are compared with the experimental measurements. The computational and experimental minimum fluidization velocities are $0.24 \mathrm{~m} / \mathrm{s}$ and $0.26 \mathrm{~m} / \mathrm{s}$ with $8 \%$ deviation. Experimental and computational pressure standard deviation also gives the same results for minimum fluidization velocity. The computational and experimental pressure drops are about 29 and 27 mbar respectively at the minimum fluidization condition. The deviation is about $7 \%$. Computational and experimental bed expansions at the minimum fluidization condition are $8 \%$ and $10 \%$ respectively. Computational solid volume fraction fluctuation is studied to predict bubble formation and bubble frequency.

For the given operating conditions, the model predictions are in good agreement with the experimental measurement. The model can be the basis for the study of flow behaviour in high temperature steam fluidized gasifiers. 


\section{References}

[1] V.Mathiesen, T.S., B.J. Hjertager, Prediction of gas particle flow with an Eulerian model including a realistic particle size distribution. Power Technology, 2000. 112: p. 34-45.

[2] Taghipour, F., Ellis, N., Wong, C., Experimental and computational study of gas-solid fluidized bed hydrodynamics. Chemical Engineering Science, 2005. 60: p. 6857-6867.

[3] Hamzehei, M., Rahimzadeh, H, Ahmadi, G., Studies of gas velocity and particle size effects on fluidized bed hydrodynamics with CFD modeling and experimental investigations. Journal of Mechanics, 2010. 26.

[4] Wachem, v.B.G.M., Schouten J.C., Krishna, R., Bleek den van C. M., Validation of the Eulerian simulated dynamic behavior of gas-solid fluidized bed. Chemical Engineering Science, 1999. 54: p. 2141-2149.

[5] Sahoo, A., Ch, R., Biswal, K.C., Experimental and computational study of the bed dynamics of semi-cylindrical gas-solid fluidized bed. Canadian Journal of Chemical Engineering, 2009. 87: p. 11-18.

[6] M.M. Kumar, E.N., CFD simulation for two-phase mixing in $2 D$ fluidized bed. Int J Adv Manf Technol, 2008.

[7] Jayarathna, S.A., Recommendation of a model for simulating and analysis of the influence of particle size distribution on the simulation of bubbling fluidized bed, in Department of Process, Energy and Environment. 2008, Telemark University College: Prosgrunn. p. 22-46.

[8] Gidaspow, D., Multiphase Flow and Fluidization. 1994, California: Academic Press Inc.

[9] Kunii, D., Levenspiel, O., Fluidization Engineering. Second ed. 1991, London: Butterworth-Heinemann. 